Check for updates

The BMJ

Cite this as: $B M J 2022 ; 376: 07$ http://dx.doi.org/10.1136/bmj.o7 Published: 05 January 2022

\title{
Omicron: South Africa says fourth wave peak has passed as it lifts curfew
}

\section{Elisabeth Mahase}

South Africa has relaxed its covid-19 restrictions as it reports that the peak of its fourth wave, this time of the omicron variant, looks likely to have passed without a spike in deaths.

The country's Department of Health reported a 29.7\% fall in the number of new cases detected in the week ending 25 December 2021 (89 781) from the previous week (127 753). ${ }^{1}$

"All indicators suggest the country may have passed the peak of the fourth wave at a national level," said the announcement of 30 December. Cases have declined in all provinces except Western Cape (up 14\%) and Eastern Cape (up 18\%), and hospital admissions have declined in all provinces except Western Cape, it said.

The findings were followed by an easing of some restrictions in South Africa, including curfew being lifted. But large gatherings are still restricted, with no more than 1000 people allowed indoors and 2000 people allowed outdoors, and masks are mandatory in all public places.

The government statement said, "While the omicron variant is highly transmissible, there have been lower rates of hospitalisation than in previous waves. This means that the country has a spare capacity for admission of patients even for routine health services. There is a marginal increase in the number of deaths in all the provinces."

\section{Less severe wave}

While early reports from South Africa have suggested that the omicron variant, which was first detected in November 2021, may be more transmissible but less severe than the previously dominant variants such as beta and delta, ${ }^{2}$ the evidence base is now starting to grow.

A preprint made available through the Lancet on 29 December compared covid-19 cases in the Gauteng province during the second wave (41 046 cases), third wave (33423), and fourth wave (133551). It found that around $4.9 \%$ of people with covid were admitted to hospital during the fourth wave, compared with $18.9 \%$ in the second wave and $13.7 \%$ in the third $(\mathrm{P}<0.001)$.

The paper also reported that $28.8 \%$ of admissions in the fourth wave were for severe disease, much lower than in the second $(60.1 \%)$ and third $(66.9 \%)$ waves $(\mathrm{P}<0.001)$.

Admitted patients in the omicron dominated fourth wave were also $73 \%$ less likely to have severe disease than patients admitted during the delta dominated third wave (adjusted odds ratio 0.27 (95\% confidence interval 0.25 to 0.31$)) .{ }^{3}$ However, the study authors warned against extrapolating these findings to other populations with different comorbidity profiles, prevalence of prior infection, and vaccination coverage, as these may be important factors.

In the UK, health leaders have emphasised that although a lower proportion of covid cases seem to be ending up in hospital, the actual number of patients could still overwhelm the health system, especially considering the apparently increased transmissibility of the omicron variant. ${ }^{4}$

1 Department of Health (South Africa). Cabinet approves changes to covid-19 regulations. 30 Dec 2021. https://sacoronavirus.co.za/2021/12/30/mediarelease-cabinet-approves-changes-to-covid-19-regulations/

2 Dyer O. Covid-19: Omicron is causing more infections but fewer hospital admissions than delta, South African data show. BM/2021;375:n3104. doi: 10.1136/bmj.n3104 pmid: 34916213

3 Jassat W, Karim SA, Mudara C, et al. Clinical severity of covid-19 patients admitted to hospitals in Gauteng, South Africa during the omicron-dominant fourth wave. Preprints with the Lancet2021 (published online 29 Dec) [preprint]. https://papers.ssrn.com/sol3/papers.cfm?abstract_id=3996320

4 Mahase E. Covid-19: Hospital admission 50-70\% less likely with omicron than delta, but transmission a major concern. BMJ2021;375:n3151. doi: 10.1136/bmj.n3151 pmid: 34952835

This article is made freely available for personal use in accordance with BMJ's website terms and conditions for the duration of the covid-19 pandemic or until otherwise determined by BMJ. You may download and print the article for any lawful, non-commercial purpose (including text and data mining) provided that all copyright notices and trade marks are retained. 